\title{
R. Tordi, Il Primo Decennio della «Revue des Deux Mondes» (1829-1839). La collaborazione di Balzac e di Sainte-Beuve
}

\section{Marco Stupazzoni}

\section{(2) OpenEdition \\ Journals}

\section{Edizione digitale}

URL: http://journals.openedition.org/studifrancesi/9998

DOI: $10.4000 /$ studifrancesi.9998

ISSN: 2421-5856

\section{Editore}

Rosenberg \& Sellier

\section{Edizione cartacea}

Data di pubblicazione: 1 août 2017

Paginazione: 376

ISSN: 0039-2944

\section{Notizia bibliografica digitale}

Marco Stupazzoni, «R. Tordi, Il Primo Decennio della «Revue des Deux Mondes» (1829-1839). La collaborazione di Balzac e di Sainte-Beuve», Studi Francesi [Online], 182 (LXI | II) | 2017, online dal 01 août 2017, consultato il 09 janvier 2021. URL: http://journals.openedition.org/studifrancesi/9998; DOI: https://doi.org/10.4000/studifrancesi.9998

Questo documento è stato generato automaticamente il 9 janvier 2021.

\section{cc) (†) $\odot$}

Studi Francesi è distribuita con Licenza Creative Commons Attribuzione - Non commerciale - Non opere derivate 4.0 Internazionale. 


\title{
R. Tordi, Il Primo Decennio della «Revue des Deux Mondes» (1829-1839). La collaborazione di Balzac e di Sainte- Beuve
}

\author{
Marco Stupazzoni
}

\section{NOTIZIA}

ROSITA TORDI, Il Primo Decennio della «Revue des Deux Mondes» (1829-1839). La collaborazione di Balzac e di Sainte-Beuve, «Studi Comparatistici» 13, anno VII, fascicolo I, gennaio-giugno 2014, pp. 111-121.

1 Fondata a Parigi nel 1829, la «Revue des Deux Mondes» ebbe tra i suoi primi collaboratori due personalità letterarie, Balzac e Sainte-Beuve, i cui destini spesso si intrecciarono con toni e ragioni anche di forte scontro polemico nel corso della loro esistenza. Oltre al saggio De la littérature industrielle del $1^{\circ}$ settembre 1839 , si ricordano soprattutto le aspre requisitorie di Sainte-Beuve contro i romanzi di Balzac, a partire dallo studio su La Recherche de l'absolu (15 novembre 1836), prima testimonianza della sostanziale inadeguatezza del critico a cogliere il senso profondo e la singolarità della poetica romanzesca balzachiana. Nel corso del biennio della sua collaborazione alla rivista (1831-1832), la cui direzione era stata assunta da François Buloz, con il quale lo scrittore ebbe, nel 1836, un acceso contenzioso a proposito della pubblicazione di Le Lys dans la vallée nella «Revue étrangère», Balzac intraprende con decisione il suo percorso letterario pubblicando L'Enfant maudit, Le Rendez-vous, Le Message e, soprattutto, La Peau de chagrin. Di non secondaria importanza è altresì la pubblicazione, nel dicembre 1830, del racconto Le Petit Souper nel quale Balzac già palesa la sua «straordinaria abilità nell'intrecciare il passato più torbido della storia di Francia all'attualità» (p. 117). Tutt'altro che trascurabile è, allo stesso tempo, il rilievo assunto nei testi pubblicati nella «Revue» dal tema della città che contribuirà a fondare e a consolidare quella 
mitologia della civiltà urbana così efficacemente celebrata da Italo Calvino a proposito di Ferragus. Un particolare interesse assume il confronto tra le diverse modalità narrative presenti nella Peau de chagrin (maggio 1831) e nel Chef-d'oeuvre inconnu (apparso in «L'Artiste» nel luglio-agosto dello stesso anno): si tratta di due opere, osserva l'A. in conclusione, che mettono a punto ed articolano la singolare coniugazione delle istanze della fantasia e della realtà che caratterizzerà in forme e in modi così potenti l'intera Comédie humaine. 